\title{
Dynamic Voltage Restorer using Matlab
}

\author{
Kunik Kumar Rajput, Sagar Bhati, Krishna Chaudhary, Chirag Dubey, Nagendra Kumar
}

\begin{abstract}
The occurrences of sag and swell in electric supply is termed as a problem of concern, since it affects the energy quality. To maintain energy quality, it is necessary to eliminate these factors to a great extent. The device used for this purpose is known as DVR which stabilizes the quality of power supply by compensating sag and swells and critical load connected to the industry remains unaffected. DVR is ideal for the application in industries because of its features i.e. low cost, small size, and its rapid response to disruption. In this work, DVR is used to eliminate voltage sag and swell and for one more application i.e. fault compensation by injecting missing voltage from the auxiliary power source.
\end{abstract}

Keywords : DVR, Sag, Fault, Swell, Compensation

\section{INTRODUCTION}

Electric supply means a pure sinusoidal voltage wave [1]. A high degree of the sinusoidal waveform is produced at the power station but due to the use of indirect devices and in error, the quality of the sinusoidal waveform is compromised and for this reason, energy efficiency devices are needed. Since power quality is critical to the performance of communication devices, heavy industrial resources, etc. Now the load requires a constant sinusoidal wave and constant frequency but due to voltage sag and swelling and slowing of supply quality is affected. Among the named disturbances voltage sags and swelling are one of the most dangerous because sensitive devices are very sensitive to short-term voltage fluctuations. Voltage sag is defined as a dip in the voltage for a very short period this can create a major problem for the equipment.

Voltage sag can cost a huge amount of money loss depending on damaged goods, circuit breakdowns, short term errors, etc. This is why we need energy-adjustment devices

Revised Manuscript Received on June 30, 2020.

* Correspondence Author

Kunik Kumar Rajput*, Electrical and Electronics Department, GL Bajaj Institute of Technology and Management, Greater Noida, India. Email: kunik19rajput@gmail.com

Sagar Bhati, Electrical and Electronics Department, GL Bajaj Institute of Technology and Management, Greater Noida, India. Email: sagarbhati06@gmail.com

Krishna Chaudhary, Electrical and Electronics Department, GL Bajaj Institute of Technology and Management, Greater Noida, India. Email: krishna78350@gmail.com

Chirag Dubey, Electrical and Electronics Department, GL Bajaj Institute of Technology and Management, Greater Noida, India. Email: chiragdubey25@gmail.com

Nagendra Kumar, Electrical and Electronics Department, GL Bajaj Institute of Technology and Management, India. Email: Nagendra.k96@gmail.com

(C) The Authors. Published by Blue Eyes Intelligence Engineering and Sciences Publication (BEIESP). This is an open access article under the CC BY-NC-ND license (http://creativecommons.org/licenses/by-nc-nd/4.0/) with critical energy. Voltage sag/swells occur as a result of a single line in-ground faults, a double line in-ground fault, or due to the start of installed motors. Most of the errors are self-explanatory but if they fail to clarify then it is everyone who breaks the correct cycle to clear the error.

\section{DYNAMIC VOLTAGE RESTORER (DVR)}

DVR is a power device used in power transmission to control the supply voltage problem. The DVR is nothing other than an inverter used to power the series power supply with an engine transformer in power supply now this injection is done with the help of high IGBT inverters. Since IGBT provides high-frequency switching which is why it provides effective control of the sags and swelling in supply [2-8].

\section{CONTROL STRATEGIES}

Following are the control strategies used in DVR to control its operation i.e. the injection/absorption of voltage to/from circuit. Typically, there are three types of power recovery strategies which depend on the type of load used. However, the best strategy is the one which use least power from the battery.

\section{A. Pre-sag Compensation Method}

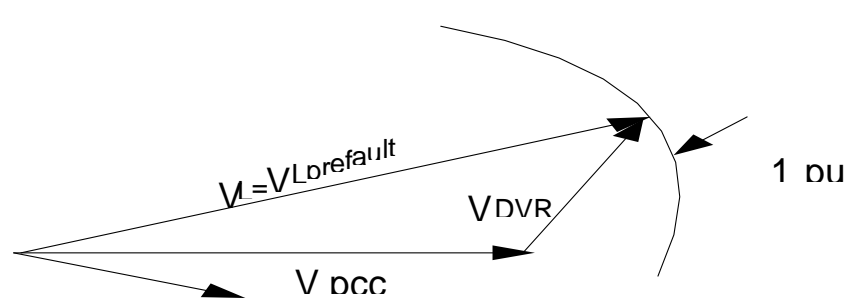

IL

Fig. 1. Vector diagram of a pre-sag method

Fig. 1 shows the vector diagram of pre sag method. It is seen from figure that pre fault voltage is $1 \mathrm{pu}$, however on the occurrence of a fault this voltage reduces to a level less than 1 $\mathrm{pu}$. This decrement in voltage is compensated by DVR which settles the voltage equal to the Perrault voltage. DVR is used to compensate the voltage as well as the angle.

Where, $\mathrm{V}_{\mathrm{L}}=$ Voltage before the fault. $\mathrm{V}_{\mathrm{DVR}}=$ Voltage injected by the DVR. Vpcc=Voltage of the bus after the fault

\section{B. In-Phase Voltage Injection Method}

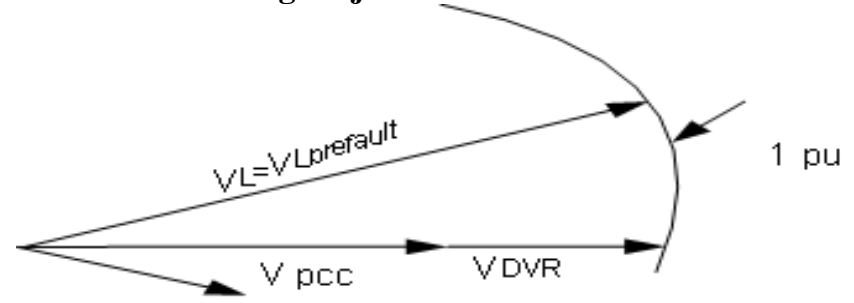

IL

Fig. 2. Vector diagram of an in-phase method 


\section{Dynamic Voltage Restorer using Matlab}

It is seen from Fig. 2 that the only difference between this method and the previous method is that the voltage injected by the DVR in the bus is in the phase with the bus voltage after the fault has occurred.

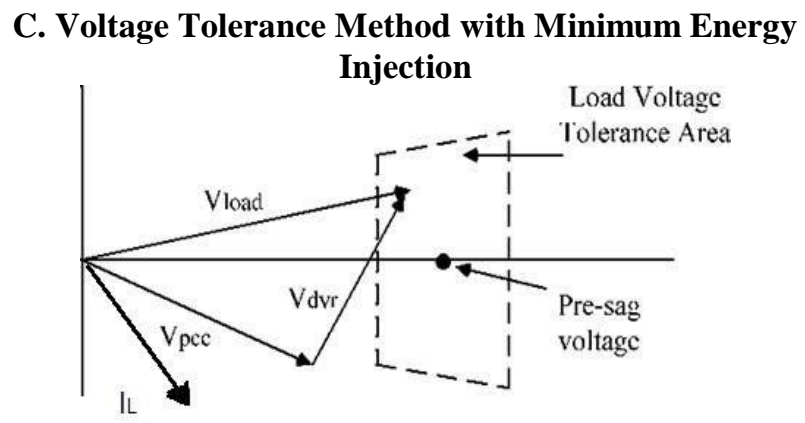

Fig. 3. Vector diagram of voltage tolerance method

\section{CONTROLLER AND SIMULATION MODEL}

The configuration of this controller is given in Fig. 4. This controller has various components like abc to d-q-0, Low pass filter, P-I controller, pulse generator. The various elements perform functions like, abc to d-q-0 is used to convert the varying 3 phase voltage to 3 phase fixed dc voltage, so that comparison of voltages can be done. The filters in this controller are generally low pass filters which are set at $50 \mathrm{~Hz}$ period.
Fig. 3 is used to describe this method. The main goal of this method is that the angle between the load current and the voltage applied by the DVR is 90 degrees. So the power input to the supply is energy efficient

$\mathrm{P}_{\text {load }}=\mathrm{V}_{\mathrm{L}} * \mathrm{I}_{\mathrm{L}} \cos \alpha$

$\mathrm{Ps}_{\text {ource }}=\mathrm{V}_{\mathrm{s}} * \mathrm{I}_{\mathrm{L}} \cos \beta$

$\mathrm{P}_{\text {inj }}=\mathrm{P}_{\text {source }}-\mathrm{P}_{\text {load }}=\mathrm{I}_{\mathrm{L}}\left(\mathrm{V}_{\mathrm{s}} \cos \beta-\mathrm{V}_{\mathrm{L}} \cos \alpha\right)$

Where, $I_{L}$ is the load current. $\alpha$ is the angle between $V_{L}$ and $I_{L}$ $\beta$ is the angle between $V_{s}$ and $I_{L}$.

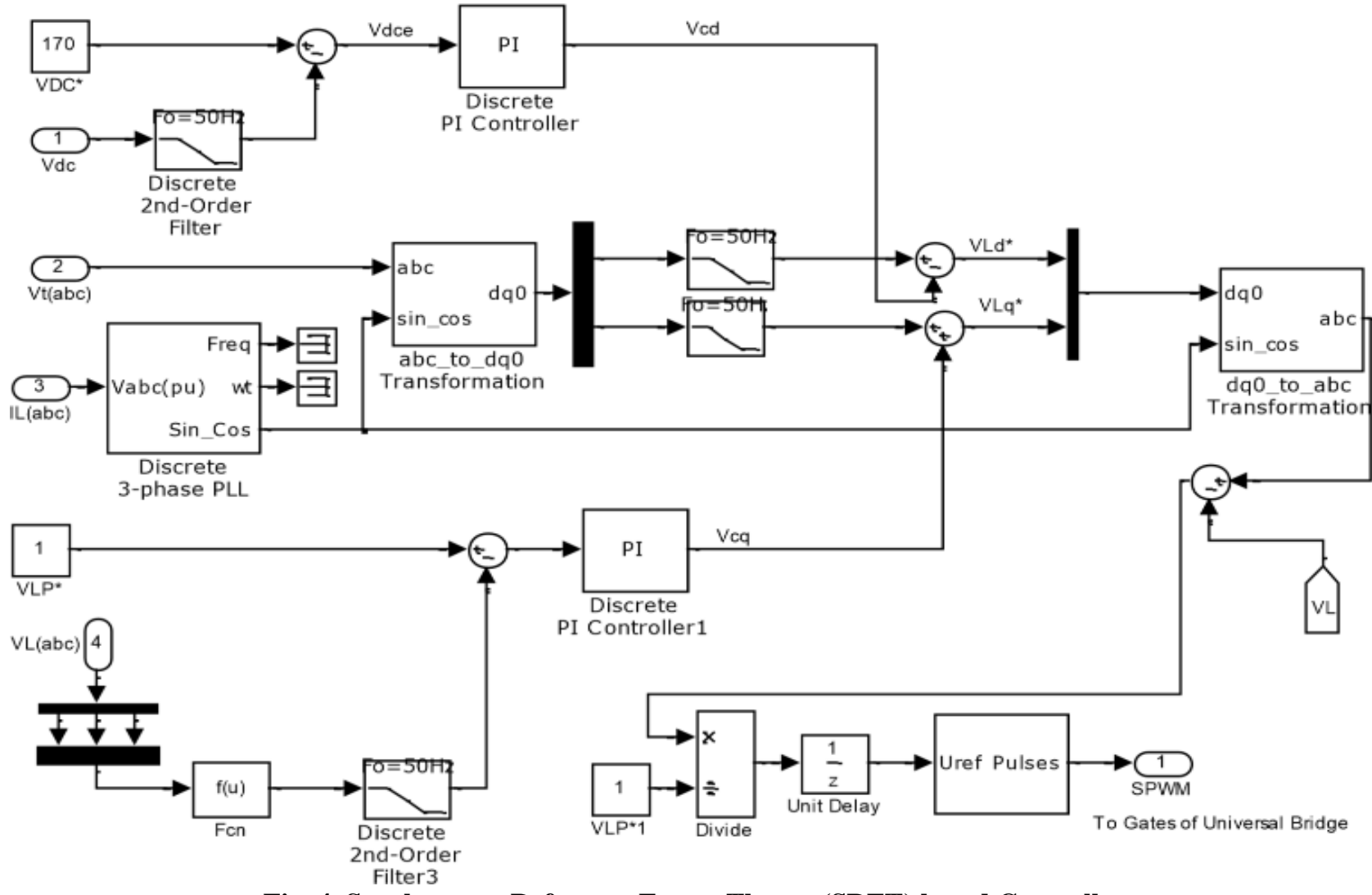

and the P-I controller is used to improve the steady-state response of the output of the DVR. Once the function of different elements is over, finally a pulse is created. Based on this pulse duration DVR open and close its switches, corresponding to the faults that have occurred during that

Fig. 4. Synchronous Reference Frame Theory (SRFT) based Controller

In Fig. 4, the value of $\mathrm{f}(\mathrm{u})$ is given by

$\mathrm{V}_{\mathrm{Lp}}=\sqrt{ } 2\left(V_{L a}{ }^{2}+V_{L b}{ }^{2}+V_{L c}{ }^{2}\right) / 3$

Where, $V_{\mathrm{Lp}}=$ Magnitude of load voltage in p.u. 

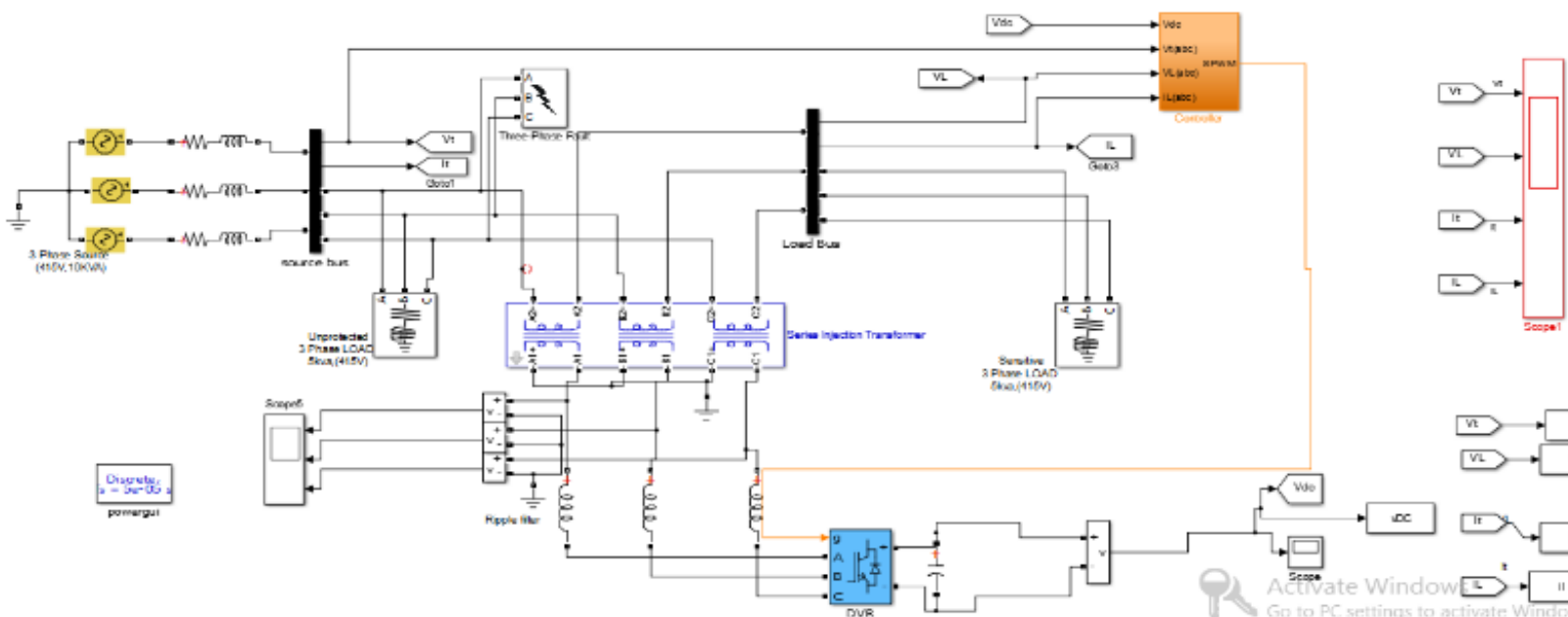

Fig. 5. Simulation Model of Fault using DVR in MATLAB

Fig. 5 shows the simulation model used in MATLAB to check the performance of DVR. It is seen that DVR is connected through the injection transformer to the transmission line.

\section{SIMULATION RESULTS}

The authors have created different faults using 3-phase creator block. The performance of DVR is noted for $\mathrm{L}-\mathrm{G}$, L-L-G, sag and Swell cases. However, in this paper there are only few results have been discussed. It is also seen from the results that DVR is working satisfactory in compensating faults as well as eliminating sag and swells from the line voltage.

Fault is termed as the condition which disturbs voltage and current of different phases. If it persists for a long time the system is subjected to severe effects.

\section{A) SINGLE LINE TO GROUND FAULT}

Single line to ground fault means the short circuit between a phase of the supply to ground. In this work, a L-G fault is created using 3-phase fault block by selecting a phase and ground only.

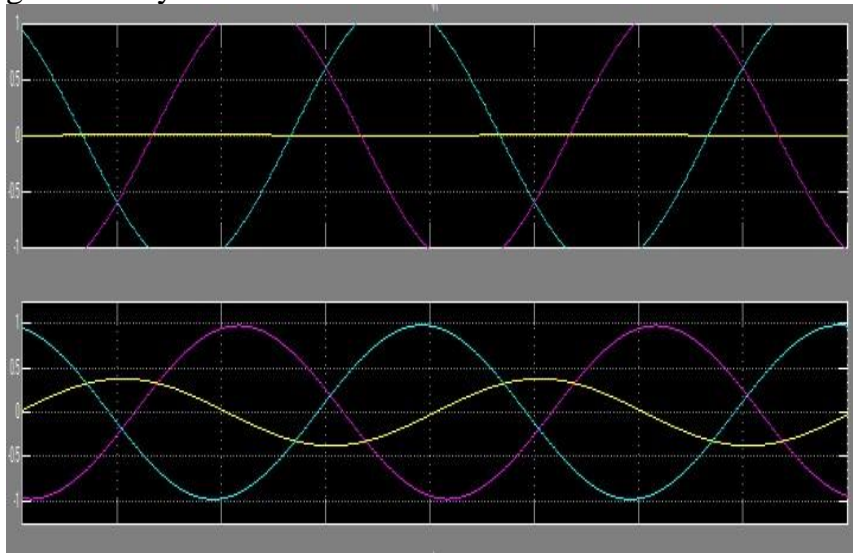

Fig. 6 Single line to ground fault

Fig 6. Shows the result associated with L-G fault. It is seen that on occurrence of this fault, that particular phase becomes short circuited and the corresponding voltage of that phase becomes zero, i.e. phase Y (yellow) in this case.

This is where DVR comes into picture. On occurrence of a fault DVR sense fault and starts functioning. DVR starts to inject the missing power into the phase which is being shorted, so that it can be compensated to its original value i.e. pre-fault value. However, it is seen that in this authors are able to compensate the fault voltage to almost $50 \%$ of the original value.

\section{B) DOUBLE LINE TO GROUND FAULT}

The performance of the DVR has also been checked on another fault case i.e. L-LG.

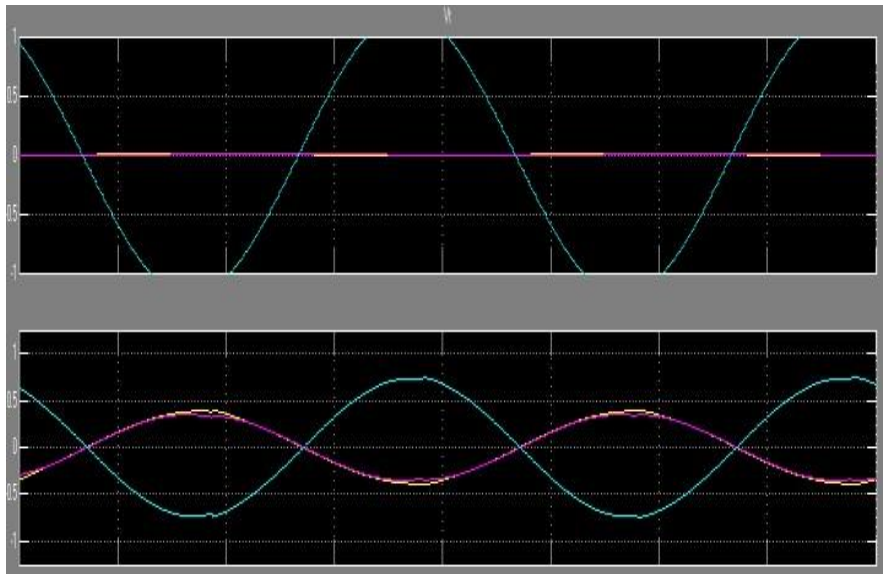

Fig. 7. Double line to ground fault

It is seen from the Fig. 7 that the voltage of both the phases i.e. $\mathrm{Y}$ and $\mathrm{R}$ become zero, once the phases have been affected by fault. In this case too, DVR is used to bring back the voltages of the faulted phases to the natural values. It is also seen that DVR compensates the voltage of the faulted phases upto $50 \%$ of the original values.

\section{C) UNBALANCE SUPPLY}

There are conditions where disturbance in supply becomes natural. This disturbed supply voltage affected the performance of various devices connected to that and ultimately cause problem in satisfactory working of the devices. Therefore, it is necessary to eliminate disturbances from the supply for power quality point of view.

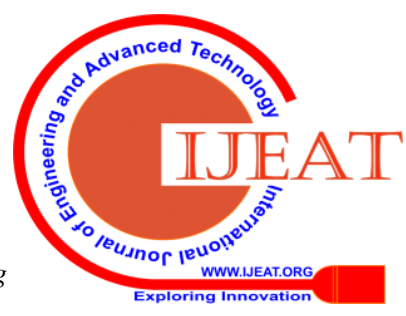




\section{Dynamic Voltage Restorer using Matlab}

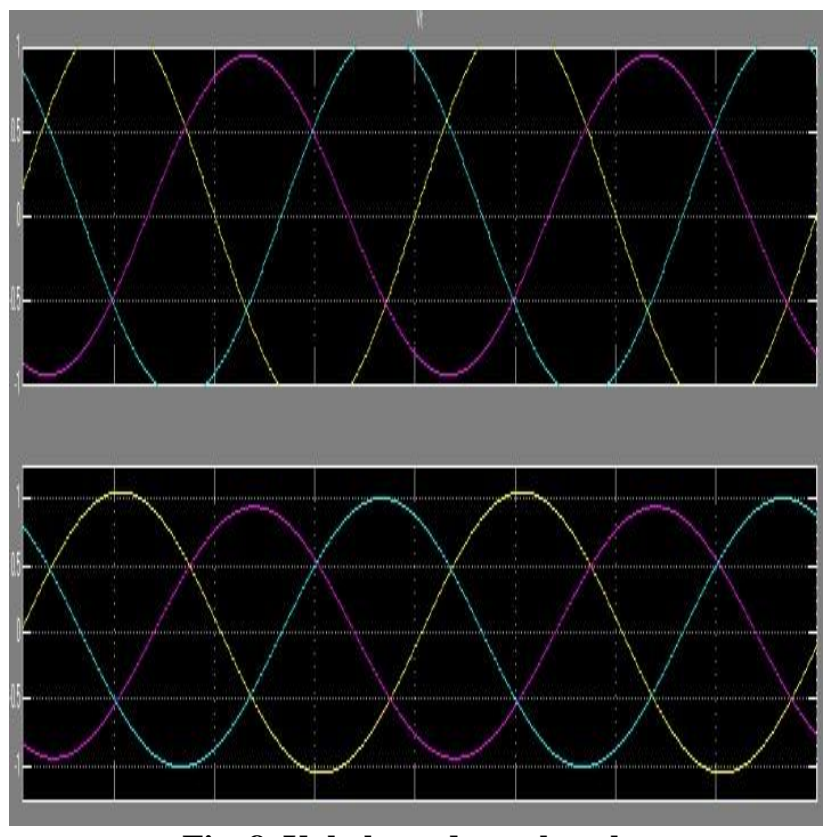

Fig. 8. Unbalanced supply voltage

Fig. 8 shows the unbalance supply and the resulted supply using DVR. It is seen that earlier unequal supply i.e. different voltages level in all phases have been seen. Some phases have voltage greater than $1 \mathrm{pu}$ while others have less than $1 \mathrm{pu}$. Using DVR the voltages in all phases become $1 \mathrm{pu}$. Therefore, a balance supply is achieved using DVR.

\section{CONCLUSION}

In this paper, authors have successfully used DVR for three different cases. The performance of DVR has been checked for faults as well as unbalance supply cases. It is seen from results that DVR is working satisfactory in all three cases. The voltage of particular phases in case of L-G or L-L-G faults have been restored to the $50 \%$ of the original value using DVR. It is also seen that using DVR the unbalance supply has been fix at the balance level. Therefore, it can be evident that DVR is an important tool in power quality context.

\section{REFERENCES}

1. N.G. Hingorani, "Introducing Custom Power", in IEEE Spectrum," Vol. 32, no. 6, pp. 4l-48, 1995.

2. P. Boonchiam, and N. Mithulananthan "Understanding of Dynamic Voltage Restorers through MATLAB Simulation" Thammasat Int. J. Sc.Tech., Vol. 11, no. 3, pp. 1-6, 2006.

3. M. Arun Bhaskar, S.S. Dash, C. Subramani , M. Jagadeesh Kumar P.R. Giresh , and M. Varun Kumar "Voltage quality improvement using DVR", in IEEE International Conference on Recent Trends in Information, Telecommunication and Computing, Kochi, Kerala, India, 12-13 March 2010.

4. Mahmoud A. El-Gammal, Amr Y. Abou-Ghazala, and Tarek I. El-Shennawy "Dynamic Voltage Restorer (Dvr) For Voltage Sag Mitigation" International Journal on Electrical Engineering and Informatics, Vol. 3, no.1, 2011.

5. Shazly A. Mohammed, Aurelio G. Cerrada, Abdel-Moamen M. 1, And B. Hasanin "Dynamic Voltage Restorer (Dvr) System for Compensation of Voltage Sags, State-Of-The-Art Review" International Journal of Computational Engineering Research, Vol. 3 no. 1, 2013.

6. A. Visser, J. Enslin, and H. Mouton, "Transformer-less Series Sag Compensation With a Cascaded Multilevel Inverter", IEEE Trans. Industrial Electronics, Vol. 49, no. 4, pp. 824-831, Aug. 2002.

7. P. Loh, M. Vilathgamuwa, S. Tang and H. Long, "Multilevel Dynamic Voltage Restorer", IEEE Power Electronics Letters, Vol. 2 , no. 4, pp. 125-130, Dec. 2004.
8. P. Roncero-Sánchez, E. Acha, J. E. Ortega-Calderon Vicente Feliu, A. García-Cerrada, "A versatile control scheme for a dynamic voltage restorer for power-quality improvement”, IEEE Trans., Power Del., Vol. 24, no. 1, pp. 277-284, Jan. 2009.

\section{AUTHORS PROFILE}

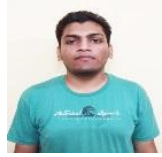

Kunik Rajput is doing his final year B.Tech. form GL Bajaj Institute of Technology \& Management Greater Noida, UP, India. His project is Dynamic Voltage Restorer using MATLAB.

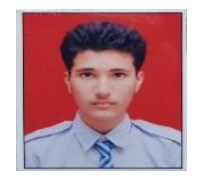

Sagar Bhati is doing his final year B.Tech. form GL Bajaj Institute of Technology \& Management Greater Noida, UP, India. His project is Dynamic Voltage Restorer using MATLAB.
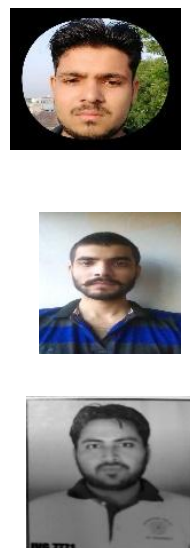

Krishna Chaudhary is doing his final B.Tech. form GL Bajaj Institute of Technology \& Management Greater Noida, UP, India. His project is Dynamic Voltage Restorer using MATLAB.

Chirag Dubey is doing his final year B.Tech. form GL Bajaj Institute of Technology \& Management Greater Noida, UP, India. His project is Dynamic Voltage Restorer using MATLAB.

Nagendra Kumar is an Associate Professor in the department of Electrical \& Electronics Engineering at GL Bajaj Institute of Technology \& Management, Greater Noida, UP, India. His research interests are Power system, control system. 